\title{
Sudden Death in Dilated Cardiomyopathy
}

\author{
AUdREY H. WU, M.D., AND SUNIL K. DAS, M.D. \\ Department of Internal Medicine, Divisions of General Medicine and Cardiology, University of Michigan Medical Center, Ann Arbor, \\ Michigan, USA
}

\begin{abstract}
Summary: The purpose of this review is to examine the potential contribution of arrhythmia to the occurrence of sudden death in dilated cardiomyopathy (DCM) and to discuss current treatment options. We performed a search of the MEDLINE database from 1985 to the present and the reference $c i-$ tations of selected articles pertaining to the prognostic significance, management, and pathophysiology of arrhythmias in DCM. A large proportion of patients with DCM die suddenly, most secondary to ventricular arrhythmia and a smaller proportion due to bradyarrhythmia. The presence and severity of ventricular ectopy may predict risk for sudden death, but the role of electrophysiologic study and signal-averaged electrocardiography in further risk stratifying patients remains uncertain. Abnormalities of the autonomic nervous system and renin-angiotensin-aldosterone axis appear to promote the occurrence of ventricular arrhythmias. Angiotensinconverting enzyme inhibitors improve overall mortality in congestive heart failure, and the use of direct angiotensin-receptor antagonists is currently being studied. In addition, beta-receptor antagonists appear to improve morbidity and may prove to improve mortality in heart failure as well. Other interventions still under investigation include amiodarone and the implantable cardioverter-defibrillator. The underlying pathophysiology of sudden death in DCM involves primarily ventricular tachyarrhythmia. Angiotensin-converting enzyme inhibitors remain a mainstay of improving overall mortality, while further study on the roles for newer drugs and devices is ongoing.
\end{abstract}

\section{Address for reprints:}

Sunil K. Das, M.D.

Department of Internal Medicine

Division of Cardiology

L3118 Womens/0273

University of Michigan Medical Center

1500 East Medical Center Drive

Ann Arbor, MI 48109, USA

Received: June 23, 1998

Accepted with revision: December 15, 1998
Key words: heart failure, sudden death, beta-receptor antagonists, angiotensin-converting enzyme inhibitors, amiodarone, implantable cardioverter-defibrillator

\section{Introduction}

Dilated cardiomyopathy (DCM) is a syndrome of impaired systolic function characterized by many hemodynamic, neurohormonal, and electrical derangements that are the end point of a diverse array of pathologic processes not related to coronary artery disease (CAD). With an estimated 2-year survival rate of $\leq 50 \%,{ }^{1,2}$ total mortality in DCM is dismal. As expected, many deaths are secondary to progressive pump failure, but even more alarming is the large proportion of patients who die suddenly or unexpectedly. Despite advances in medical management that reduce overall mortality associated with congestive heart failure (CHF), the mortality rate from sudden death has remained unchanged at 30 to $40 \%$ of all deaths. ${ }^{1-3}$ The key to reducing the high incidence of sudden death in this population is to understand the underlying pathophysiology. and investigation has focused primarily upon the role of arrhythmia. Although the presence of ventricular tachycardia (VT) identifies the patient with $\mathrm{CAD}$ who is at risk for sudden death, ${ }^{4}$ no such relation has been definitively established in the patient with CHF in the absence of CAD. Further complicating the issue and making comparisons among different studies difficult is the inconsistent and sometimes arbitrary definition of sudden death. Previously proposed definitions that have been utilized in various studies include classification by apparent etiology (circulatory failure or arrhythmia), ${ }^{5}$ death occurring within $24 \mathrm{~h}$ of symptom onset, and witnessed deaths within $1 \mathrm{~h}$ of symptom onset. ${ }^{6}$ The purpose of this review is to examine the potential contribution of arrhythmia to the occurrence of sudden death in the patient with DCM and to discuss current treatment options.

\section{Sudden Cardiac Death}

In several small series of unselected patients who experienced sudden death, VT or ventricular fibrillation (VF) is generally the most frequently encountered terminal rhythm, al- 
though roughly one quarter of events appears to be associated with bradyarrhythmias. ${ }^{7-9}$ In patients with and without $C A D$ hospitalized for heart transplant evaluation, one series observed that bradycardia or electromechanical dissociation was in fact the predominant rhythm at the time of arrest, with no definite cause for arrest identified in approximately one half of those cases. ${ }^{10}$ The pathophysiology of bradyarrhythmic arrests is not well elucidated, although neural reflex activity has been implicated."

\section{Predictive Testing: Electrophysiologic Study and Signal-Averaged Electrocardiogram}

In patients with DCM, there is a high prevalence of ventricular arrhythmia. Nearly all patients demonstrate some form of ventricular ectopy on ambulatory electrocardiographic (ECG) monitoring, and at least half of these episodes qualify as nonsustained ventricular tachycardia (NSVT) ${ }^{12-14}$ Some observational studies have suggested that the occurrence of NSVT in patients with DCM identifies a subgroup at high risk for sudden death. ${ }^{5}{ }^{15}$ particularly in the setting of severely decreased left ventricular ejection fraction (LVEF) ${ }^{16}$ However, it is more likely that ventricular ectopy merely indicates globally impaired myocardial function rather than the presence of potentially arrhythmogenic foci, and the majority of studies have failed to demonstrate any correlation between either the presence or the severity of ventricular arrhythmias and the risk for sudden death. 12, 14, 17

Although inducibility of VT on electrophysiologic study (EPS) has been found to predict risk for sudden death in patients with ischemic heart disease, ${ }^{18}$ the role of EPS in the risk stratification of patients with impaired LVEF not associated with CAD remains controversial. Induction of ventricular arrhythmias does not correlate consistently with clinical or ECG criteria, including degree of LVEF dysfunction and severity of ventricular ectopy. ${ }^{19,20}$ While the presence of polymorphic VT on EPS does not predict risk for sudden death in DCM, the induction of sustained monomorphic VT appears to identify high-risk patients. ${ }^{21}$ However, even if positive EPS were a useful prognostic indicator, the lack of inducible VT does not necessarily predict freedom from sudden death,,$^{22}$ as at least one third of patients with DCM with a history of sustained VT cannot be induced by EPS. ${ }^{23,24}$ In addition, suppression or stabilization of induced arrhythmias by EPS-guided drug treatment does not lower risk of recurrent arrhythmia or sudden death. ${ }^{25-27}$

Another frequently studied prognostic tool is the signalaveraged ECG (SAE) as a measure of autonomic dysfunction in the patient with CHF. In the population with DCM, conclusions regarding the validity of SAE in predicting risk for sudden death have been contradictory, but SAE appears not to be a useful prognostic indicator. Heart rate variability correlates with severity of left ventricular dysfunction and risk for death secondary to pump failure ${ }^{28}$ but does not significantly predict risk or sudden death. ${ }^{28-30}$ Some investigators have found a strong correlation between an abnormal SAE and inducible
VT on EPS, but the prevalence of both events was low ${ }^{27}$ and. as noted previously, the significance of induced VT in patients with DCM is not well established.

\section{Influence of the Autonomic Nervous System}

Activation of the sympathetic nervous system is a well documented phenomenon associated with CHF. Plasma norepinephrine levels are significantly higher in patients with $\mathrm{CHF}$ than in normal controls, ${ }^{31}$ with levels in ischemic and nonischemic heart disease being similarly elevated, ${ }^{32.33}$ although the level of plasma norepinephrine levels may ${ }^{31}$ or may not ${ }^{32}$ correlate with severity of heart failure. As has been observed in ischemic heart disease, ${ }^{34-36}$ heightened sympathetic activity may precipitate or predispose the patient with heart failure to potentially fatal arrhythmia. ${ }^{34}$ Studies of unselected populations of sudden death victims have demonstrated a circadian pattern of events, with the highest incidence of events occurring during the morning hours, ${ }^{37}$ a timing which appears to correspond to a daily rise in catecholamine levels ${ }^{38}$ and associated platelet aggregability. ${ }^{39} \mathrm{~A}$ similar diurnal pattern of sudden death incidence has been observed in patients with CHF without CAD.40

The first large-scale multicenter trial examining the effect of beta blockers in DCM, the Metoprolol in Dilated Cardiomyopathy (MDC) Trial found that metoprolol was well tolerated and appeared to prevent clinical decline. However, the study was not large enough to demonstrate conclusively improved survival with metoprolol, and no significant effect on sudden death mortality was observed. ${ }^{41}$ Patients with heart failure treated with the beta-1 selective antagonist bisoprolol in the Cardiac Insufficiency Bisoprolol Study (CIBIS) demonstrated improved functional capacity, with possibly greater benefit in those patients without CAD, but again no survival benefit was observed. ${ }^{42}$ Newer beta blocker, carvedilol, possesses several unique properties: peripheral vascular resistance is reduced via alpha-1 blockade, while subsequent reflex tachycardia is prevented by its primary action of beta-1 antagonism. Furthermore, carvedilol also demonstrates a significant antioxidant action. ${ }^{43}$ In a recent multicenter trial, the use of carvedilol in chronic CHF significantly reduced total as well as sudden death mortality. This effect was seen in all subgroups analyzed, including those with ischemic and dilated cardiomyopathy and with varying degrees of heart failure. ${ }^{44}$ Smaller trials have shown slowing of disease progression in mild to moderate heart failure ${ }^{45,46}$ and symptomatic and hemodynamic improvement in severe $\mathrm{CHF}^{47}$ Again, these benefits were seen to similar degrees in both nonischemic and ischemic populations, but in general these trials have been too small to judge mortality end points. Larger trials will be needed to assess the effect of beta blockers on mortality.

\section{Influence of the Renin-Angiotensin-Aldosterone Axis}

Angiotensin-converting enzyme (ACE) inhibitors have been shown to improve overall mortality in patients with 
symptomatic $\mathrm{CHF}^{48-50}$ and to decrease the incidence of symptomatic heart failure in patients with decreased LVEF.51 The results of Vasidilator-Heart Failure Trial II (VHeFT II) suggest that there may be some benefit in sudden death mortality for patients with DCM and in general for those with less severe CHF. On the other hand, the significant mortality benefits seen in Studies of Left Ventricular Dysfunction (SOLVD)-Treatment and Cooperative North Scandinavian Enalapril Survival Study (CONSENSUS) and the trend in SOLVD-Prevention were primarily due to improvement in death rates from progressive pump failure. Differences in study groups and design may account for these findings. The study population of VHeFT II was roughly half with DCM, while those of SOLVD-Treatment, CONSENSUS, and SOLVD-Prevention were largely patients with $\mathrm{CAD}$. Also, the two study arms of VHeFT II were vasodilator drug therapy rather than ACE inhibitor versus placebo.

In addition to their hemodynamic effects, ACE inhibitors may possess antiarrhythmic properties as well, although this finding has been better demonstrated in the population with ischemic CHF. Captopril prolongs ventricular refractoriness and repolarization on EPS in patients with ischemic $\mathrm{CHF}$ and inducible $\mathrm{VT},{ }^{52}$ and reduces both norepinephrine overflow and arrhythmias in the isolated rat heart during reperfusion. ${ }^{53}$ Enalapril in comparison with placebo has been shown to reduce significantly the frequency of ventricular ectopy, including episodes of VT, in patients with DCM. ${ }^{54} \mathrm{~A}$ small group of patients with CHF treated with an ACE inhibitor demonstrated restored heart rate variability, reflective of improved parasympathetic activity, which may be protective against fatal ventricular arrhythmias. .55

Angiotensin II type 1 receptor antagonists such as losartan have recently emerged as a new treatment option for $\mathrm{CHF}$. The Evaluation of Losartan in the Elderly (ELITE) study compared treatment with losartan and captopril in elderly patients with symptomatic heart failure and in patients with DCM comprising approximately one third of the study population. There appeared to be a significant decrease in total mortality, primarily due to reduction in sudden deaths, a finding consistent in both ischemic cardiomyopathy and DCM subgroups. ${ }^{56}$ Future trials using larger populations and longer follow-up periods will be required to establish any definite survival benefit.

Recent interest has also focused on the direct antagonism of aldosterone in the treatment of CHF, as aldosterone may contribute to potassium and magnesium loss and subsequent fatal arrhythmia, impaired myocardial norepinephrine uptake, ${ }^{57}$ and increased myocardial collagen turnover and fibrosis. ${ }^{58}$ The ongoing Randomized Aldactone Evaluation Study (RALES) will investigate the mortality benefit of adding aldactone to conventional heart failure therapy. ${ }^{59}$

\section{Amiodarone}

Classified as a class III antiarrhythmic agent, amiodarone prolongs repolarization and the refractory period in all cardiac tissue. In addition to this fundamental action, amiodarone pos- sesses an antifibrillatory effect, both alpha- and beta-blocking properties, and a minor negative inotropic effect. ${ }^{60}$ Amiodarone has shown promise as an antiarrhythmic agent, but its role in the treatment of patients with impaired left ventricular function is still being studied. In a prospective, nonblinded design, the Grupo de Estudio de la Sobrevida en la Insuficiencia Cardiaca en Argentina (GESICA) trial demonstrated improved mortality in patients with severe CHF on low-dose amiodarone. Both sudden death and death due to progressive heart failure were reduced in all subgroups analyzed, including New York Heart Association (NYHA) functional class and presence or absence of NSVT on Holter monitoring. Although approximately $20 \%$ of the study population were patients with DCM, mortality in these patients was not analyzed separately. ${ }^{61}$ Singh et al ${ }^{62}$ found no significant effect of lowdose amiodarone on sudden death or overall mortality, although there appeared to be a favorable trend toward survival benefit in the treatment of DCM. In smaller trials examining both ischemic and DCM populations, the use of amiodarone significantly reduced ventricular ectopy on ambulatory ECG monitoring, ${ }^{63,64}$ but suppression of ventricular arrhythmia has not been associated with improvement in overall or sudden death mortality. ${ }^{62.63}$

\section{Implantable Cardioverter-Defibrillators}

Given the significant role of ventricular arrhythmias in sudden cardiac death, it would seem logical that the implantable cardioverter-defibrillator (ICD) would improve survival rates. Patients with DCM who have ICDs in place may have a rate of sudden death as low as $2 \%$ per year ${ }^{65}$ and have similar sudden death rates as patients with ischemic CHF who have a history of cardiac arrest, a group with known survival benefit from ICD placement. ${ }^{66}$ Several small nonrandomized studies investigating ICD placement in patients with a history of cardiac arrest or recurrent, refractory VT or VF have suggested a resultant decrease in the occurrence of sudden death in mixed populations of patients with both ischemic and nonischemic $\mathrm{CHF}^{67,68}$ and in those with $\mathrm{DCM} .{ }^{23}$ In comparing three treatment options for patients referred for cardiac transplant evaluation-ICD placement versus antiarrhythmic treatment versus no antiarrhythmic treatment-Sweeney $\mathrm{et} \mathrm{al} .^{69}$ found that sudden death rates were lowest in the ICD group regardless of the etiology of CHF, but that total mortality was similar in all three treatment groups. These findings raise the question of the ultimate utility of ICD use in prolonging survival in patients with CHF: the net result may be to reduce the occurrence of sudden death only to increase the number of patients living long enough to die of progressive heart failure.

Recent trials have compared ICD placement with antiarrhythmic treatment. In the Antiarrhythmics Versus Implantable Defibrillators (AVID) study, patients with a history of VF or hemodynamically significant VT in conjunction with $L V E F \leq 0.40$ were randomized to ICD versus amiodarone or sotalol. Patients treated with ICD demonstrated lower overall mortality than those treated with antiarrhythmic medication. 
Mean LVEF for the two treatment arms were 0.32 and 0.31 (defibrillator and antiarrhythmic groups, respectively), and the proportions of subjects with CAD were identical ( $81 \%$ ); a separate analysis was not performed for patients with DCM in this study. ${ }^{70}$ Currently ongoing, the Cardiomyopathy Trial (CAT) will examine prophylactic ICD placement in patients with severe DCM who do not have a history of symptomatic ventricular arrhythmias. ${ }^{71}$

\section{Conclusion}

Sudden death in DCM remains a clinical problem of considerable importance. Ventricular arrhythmias play a prominent part in the pathophysiology of sudden death, and the optimal method of identifying patients at risk and improving prognosis is still undefined. The frequency of ventricular ectopy in patients with CHF may merely reflect the severity of left ventricular dysfunction and degree of sympathetic activation rather than represent an independent marker of risk. The exact role for EPS and SAE in the risk stratification of patients with CHF also remains to be established, particularly in light of data questioning the significance of inducible ventricular arrhythmias and the utility of suppressing induced arrhythmias in improving mortality. Angiotensin-converting enzyme inhibitors improve mortality secondary to progressive heart failure and remain a mainstay of medical treatment for $\mathrm{CHF}$. Newer agents such as carvedilol and losartan, while showing promise in reducing heart failure morbidity and mortality, have not been definitively demonstrated in large, randomized control trials to affect incidence of sudden death. Initial data on the ICD suggest improved sudden death mortality, but use of this intervention may in turn result in increased incidence of death from progressive heart failure. Further study will be required to determine the effect of these treatment modalities on sudden death mortality in DCM.

\section{References}

I. Likoff MJ, Chandler SL, Kay HR: Clinical determinants of mortality in chronic congestive heart failure secondary to idiopathic dilated or to ischemic cardiomyopathy. Am J Cardiol 1987;59:634-638

2. Franciosa JA, Wilen M, Ziesche S, Cohn JN: Survival in men with severe chronic left ventricular failure due to either coronary artery disease or idiopathic dilated cardiomyopathy. Am J Cardiol 1987; 59:831-836

3. Unverferth DV, Magorien RD, Moeschberger ML, Baker PB, Fetters JK, Leier CV: Factors influencing the one-year mortality of dilated cardiomyopathy. Am J Cardiol 1984;54:147-152

4. Richards DAB, Byth K, Ross DL, Uther JB: What is the best predictor of spontaneous ventricular tachycardia and sudden death after myocardial infarction? Circulation 1991;83:756-763

5. Hinkle LE, Thaler HT: Clinical classification of cardiac deaths. Circulation 1982;65:457-464

6. Goldstein $\mathrm{S}$ : The necessity of a uniform definition of sudden coronary death: Witnessed death within 1 hour of the onset of acute symptoms. Am Heart J 1982;103:156-159

7. Iseri LT, Humphrey SB, Siner EJ: Prehospital brady-asystolic arrest. Ann Intern Med 1978;88:741-745
8. Nikolic G, Bishop RL, Singh JB: Sudden death recorded during Holter monitoring. Circulation 1982;66:218-225

9. Kempf FC, Josephson ME: Cardiac arrest recorded on ambulatory electrocardiographs. Am J Cardiol 1984;53:1577-1 582

10. Luu M, Stevenson WG, Stevenson LW, Baron K. Walden J: Diverse mechanisms of unexpected cardiac arrest in advanced heart failure. Circulation 1989;80:1675-1680

11. Milstein S, Buetikofer J, Lesser J, Goldenberg IF, Benditt DG, Gornick C, Reyes WJ: Cardiac asystole: A manifestation of neurally mediated hypotension-bradycardia. J Am Coll Cardiol 1989:14: 1626-1632

12. Olshausen KV, Schafer A, Mehmel HC, Schwarz F, Senges J, Kubler W: Ventricular arrhythmias in idiopathic dilated cardiomyopathy. Br Heart J 1984;51:195-201

13. Maskin CS, Siskind SJ, LeJemtel TH: High prevalence of nonsustained ventricular tachycardia in severe congestive heart failure. Am Heart J 1984; 107:896-901

14. Huang SK, Messer JV, Denes P: Significance of ventricular tachycardia in idiopathic dilated cardiomyopathy: Observations in 35 patients. Am J Cardiol 1983;51:507-512

15. Meinertz T, Treese N, Kasper W, Geibel A, Hofmann T, Zehender M, Bohn D, Pop T, Just H: Determinants of prognosis in idiopathic dilated cardiomyopathy as determined by programmed electrical stimulation. Am J Cardiol 1985;56:337-341

16. Gradman A, Deedwania P, Cody R, Massie B, Packer M, Pitı B. Goldstein S: Predictors of total mortality and sudden death in mild to moderate heart failure. J Am Coll Cardiol 1989;14:564-570

17. Wilson JR, Schwartz S, St John Sutton M, Ferraro N. Horowitz LN, Reichek N, Josephson ME: Prognosis in severe heart failure: Relation to hemodynamic measurements and ventricular ectopic activity. J Am Coll Cardiol 1983;2:403-410

18. Wilber DJ, Olshansky BR, Moran JF, Scanlon PJ: Electrophysiological testing and nonsustained ventricular tachycardia: Use and limitations in patients with coronary artery disease and impaired left ventricular function. Circulation 1990;82:350-358

19. Spielman SR, Greenspan AM, Kay HR, Discigil K, Webb CR, Sokoloff NM, Rae AP, Morganroth J, Horowitz LN: Electrophysiology testing in patients at high risk for sudden cardiac death. I. Nonsustained ventricular tachycardia and abnormal ventricular function. J Am Coll Cardiol 1985;6:31-39

20. Kron J, Hart M, Schual-Berke S, Niles NR, Hosenpud JD, McAnulty JH: Idiopathic dilated cardiomyopathy: Role of programmed electrical stimulation and Holter monitoring in predicting those at risk of sudden death. Chest 1988;93:85-90

21. Das SK, Morady F, DiCarlo L, Baerman J, Krol R, de Buitleir M. Crevey B: Prognostic usefulness of programmed ventricular stimulation in idiopathic dilated cardiomyopathy without symptomatic ventricular arrhythmias. Am J Cardiol 1986;58:998-1000

22. Buxton AE, Marchlinski FE, Waxman HL, Flores BT, Cassidy DM, Josephson ME: Prognostic factors in nonsustained ventricular tachycardia. Am J Cardiol 1984;53:1275-1279

23. Fazio G, Veltri EP, Tomaselli G, Lewis R, Griffith LSC, Guarnieri $T$ : Long-term follow-up of patients with nonischemic dilated caldiomyopathy and ventricular tachyarrhythmias treated with implantable cardioverter defibrillators. PACE 1991:14:1905-1910

24. Naccarelli GV, Prystowsky EN, Jackman WM, Heger JJ, Rahilly GT, Zipes DP: Role of electrophysiology testing in managing patients who have ventricular tachycardia unrelated to coronary artery disease. Am J Cardiol 1982;50:165-171

25. Poll DS, Marchlinski FE, Buxton AE, Doherty JU, Waxman HL, Josephson ME: Sustained ventricular tachycardia in patients with idiopathic dilated cardiomyopathy: Electrophysiology testing and lack of response to antiarrhythmic drug therapy. Circulation 1984; $70: 451-456$

26. Milner PG, DiMarco JP, Lerman BB: Electrophysiological evaluation of sustained ventricular tachycardia in idiopathic dilated cardiomyopathy. PACE 1988;11:562-568

27. Turitto G, Ahuja RK, Caref EB, El-Sherif N: Risk stratification for arrhythmic events in patients with nonischemic dilated cardiomy- 
opathy and nonsustained ventricular tachycardia: Role of programmed ventricular stimulation and the signal-averaged electrocardiogram. J Am Coll Cardiol 1994;24:1523-1528

28. Fauchier L, Babuty D, Cosnay P, Autret ML, Fauchier JP: Heart rate variability in idiopathic dilated cardiomyopathy: Characteristics and prognostic value. J Am Coll Cardiol 1997;30:1009-1014

29. Szabo BM, van Veldhuisen DJ, van der Veer N, Brouwer J, De Graeff PA, Crijns HJ: Prognostic value of heart rate variability in chronic congestive heart failure secondary to idiopathic or ischemic dilated cardiomyopathy. Am J Cardiol 1997;79:978-980

30. Silverman ME, Pressel MD, Brackett JC, Lauria SS, Gold MR, Gottlieb SS: Prognostic value of the signal-averaged electrocardiogram and a prolonged QRS in ischemic and nonischemic cardiomyopathy. Am J Cardiol 1995;75:460-464

31. Levine TB, Francis GS, Goldsmith SR, Simon AB, Cohn JN: Activity of the sympathetic nervous system and renin-angiotensin system assessed by plasma hormone levels and their relation to hemodynamic abnormalities in congestive heart failure. Am J Cardiol 1982;49:1659-1660

32. Viquerat CE, Daly P, Swedberg K, Evers C, Curran D, Parmley WW, Chatterjee K: Endogenous catecholamine levels in chronic heart failure: Relation to the severity of hemodynamic abnormalities. Am J Med 1985;78:455-460

33. Thomas JA, Marks BH: Plasma norepinephrine in congestive heart failure. Am J Cardiol 1978;41:233-243

34. Meredith IT, Broughton A, Jennings GL, Esler MD: Evidence of a selective increase in cardiac sympathetic activity in patients with sustained ventricular arrhythmias. $N$ Engl J Med 1991;325: 618-624

35. Kliks BR, Burgess MJ, Abildskov JA: Influence of sympathetic tone on ventricular fibrillation threshold during experimental coronary occlusion. Am J Cardiol 1975;36:45-49

36. Lombardi F, Verrier RL, Lown B: Relationship between sympathetic neural activity, coronary dynamics and vulnerability to ventricular fibrillation during myocardial ischemia and reperfusion. Am Heart J 1983;105(6):958-965

37. Muller JE, Ludmer PL, Willich SN, Tofler GH, Aylmer G, Klangos I, Stone PH: Circadian variation in the frequency of sudden cardiac death. Circulation 1987;75(1):131-138

38. Peters RW: Circadian patterns and triggers of sudden cardiac death. Cardiol Clin 1996;14:185-194

39. Tofler GH, Brezinski D, Schafer AI, Czeisler CA, Rutherford JD, Willich SN, Gleason RE, Williams GH, Muller JE: Concurrent morning increase in platelet aggreggability and the risk of myocardial infarction and sudden cardiac death. N Engl J Med 1987; 316:1514-1518

40. Moser DK, Stevenson WG, Woo MA, Stevenson LW: Timing of sudden death in patients with heart failure. I Am Coll Cardiol. 1994;24:963-967

41. Waagstein F, Bristow MR, Swedberg K, Camerini F, Fowler MB, Silver MA, Gilbert EM, Johnson MR, Goss FG, Hjalmarson A, for the Metoprolol in Dilated Cardiomyopathy (MDC) Trial Study Group: Beneficial effects of metoprolol in idiopathic dilated cardiomyopathy. Lancer 1993;342:1441-1446

42. CIBIS Investigators and Committees: A randomized trial of betablockade in heart failure: The Cardiac Insufficiency Bisporolol Study (CIBIS). Circulation 1994;90:1765-1773

43. Feuerstein GZ, Ruffolo RR: Carvedilol, a novel multiple action antihypertensive agent with antioxidant activity and the potential for myocardial and vascular protection. Eur Heart J 1995; 16(suppl F): $38-42$

44. Packer M, Bristow MR, Cohn JN, Colucci WS, Fowler MB, Gilbert EM, Shusterman NH for the U.S. Carvedilol Heart Failure Study Group: The effect of carvedilol on morbidity and mortality in patients with chronic heart failure. $N$ Engl J Med 1996;334: 1349-1355

45. Colucci WS, Packer M, Bristow MR, Gilbert M, Cohn JN, Fowler MB, Krueger SK, Hershberger R, Uretsky BF, Bowers JA, Sackner-Bernstein JD, Young ST, Holcslaw TL, Lukas MA, for the U.S.
Carvedilol Heart Failure Study Group: Carvedilol inhibits clinical progression in patients with mild symptoms of heart failure. Circulation 1996;94:2800-2806

46. Bristow MR, Gilbert EM, Abraham WT, Adams KF, Fowler MB, Hershberger RE, Kubo SH, Narahara KA, Ingersoll H, Krueger S, Young S, Shusterman N, for the MOCHA Investigators: Carvedilol produces dose-related improvements in left ventricular function and survival in subjects with chronic heart failure. Circulation 1996;94:2801-2816

47. Krum H, Sackner-Bernstein JD, Goldsmith RL. Kukin ML, Schwartz B, Penn J, Medina N, Yushak M, Horn E. Katz SD, Levin HR, Neuberg GW, DeLong G, Packer M: Double-blind, placebocontrolled study of the long-term efficacy of carvedilol in patients with severe chronic heart failure. Circulation 1995;92:1499-1506

48. Cohn JN, Johnson G, Ziesche S, Cobb F, Francis G, Tristani F, Smith R, Dunkman WB, Loeb H, Wong M, Bhat G, Goldman S, Fletcher RD, Doherty J, Hughes CV, Carson P. Cintron G, Shabetai $\mathrm{R}$, Haakenson C: A comparison of enalapril with hydralazineisosorbide dinitrate in the treatment of chronic congestive heart failure. NEngl J Med 1991;325:303-310

49. The SOLVD Investigators: Effect of enalapril on survival in patients with reduced left ventricular ejection fractions and congestive heart failure. N Engl J Med 1991;325:293-302

50. The CONSENSUS Trial Study Group: Effects of enalapril on mortality in severe congestive heart failure: Results of the Cooperative North Scandinavian Enalapril Survival Study (CONSENSUS). $N$ Engl JMed 1987;316:1429-1435

51. The SOLVD Investigators: Effect of enalapril on mortality and the development of heart failure in asymptomatic patients with reduced left ventricular ejection fractions. N Engl JMed 1992;327:685-691

52. Bashir Y, Sneddon JF, O'Nunain S, Paul VE, Gibson S, Ward DE. Camm AJ: Comparative electrophysiological effects of captopril or hydralazine combined with nitrate in patients with left ventricular dysfunction and inducible ventricular tachycardia. $\mathrm{Br} \mathrm{Heart} \mathrm{J}$ 1992;67:355-360

53. Gilst WHV, de Graff PA, Wesseling H, de Langen CDJ: Reduction of reperfusion arrhythmias in the ischemic isolated rat heart by angiotensin converting enzyme inhibitors: A comparison of captopril. enalapril, and HOE 498. J Cardiovasc Pharm 1986;8:722-728

54. Webster MWI, Fitzpatrick A, Nicholls MG, Ikram H, Wells JE: Effect of enalapril on ventricular arrhythmias in congestive heart failure. Am J Cardiol 1985;56:566-569

55. Binkley PF, Haas GJ, Starling RC, Nunziata E, Hatton PA, Leier $\mathrm{CV}$, Cody RJ: Sustained augmentation of parasympathetic tone with angiotensin-converting enzyme inhibition in patients with congestive heart failure. J Am Coll Cardiol 1993;21:655-661

56. Pitt B, Segal R, Martinez FA, Meurers G. Cowley AJ, Thomas I. Deedwania PC, Ney DE, Snavely DB, Chang PI on behalf of ELITE Study Investigators: Randomised trial of losartan versus captopril in patients over 65 with heart failure (Evaluation of Losartan in the Elderly Study, ELITE). Lancet 1997:349:747-752

57. Barr CS, Lang CC, Hanson J, Arnott M, Kennedy N. Struthers AD: Effects of adding spironolactone to an angiotensin-converting enzyme inhibitor in chronic congestive heart failure secondary to coronary artery disease. Am J Cardiol 1995;76:1259-1265

58. MacFadyen RJ, Barr CS, Struthers AD: Aldosterone blockade reduces vascular collagen turnover, improves heart rate variability and reduces early morning rise in heart rate in heart failure patients. Cardiovasc Res 1997;35:30-34

59. Pitt B: "Escape" of adosterone production in patients with left ventricular dysfunction treated with an angiotensin converting enzyme inhibitor: Implications for therapy. Cardiovasc Drugs Ther 1995;9: $145-149$

60. Freedman MD, Somberg JC: Pharmacology and pharmacokinetics of amiodarone. J Clin Pharmacol 1991;31:1061-1069

61. Doval HC, Nul DR, Grancelli HO, Perrone SV, Bortman GR, Curiel $R$ for Grupo de Estudio de la Sobrevida en la Insuficiencia Cardiaca en Argentina (GESICA): Randomised trial of low-dose 
amiodarone in severe congestive heart failure. Lancet 1994;344: 493-498

62. Singh SN, Fletcher RD, Fisher SG, Singh BN, Lewis HD, Deedwania PC, Massie BM, Colling C, Lazzeri D, for the Survival Trial of Antiarrhythmic Therapy in Congestive Heart Failure: Amiodarone in patients with congestive heart failure and asymptomatic ventricular arrhythmia. $N$ Engl J Med 1995;333:77-82

63. Nicklas JM, McKenna WJ, Stewart RA, Mickelson JK, Das SK, Schork A, Krikler SJ, Quain LA, Morady F, Pitt B: Prospective, double-blind, placebo-controlled trial of low-dose amiodarone in patients with severe heart failure and asymptomatic frequent ventricular ectopy. Am Heart J 1991;122:1016-1021

64. Neri R, Mestroni L, Salvi A, Pandullo C, Camerini F: Ventricular arrhythmias in dilated cardiomyopathy: Efficacy of amiodarone. Am Heart J 1987;113:707-715

65. Grimm W, Marchlinski FE: Shock occurrence and survival in 49 patients with idiopathic dilated cardiomyopathy and an implantable cardioverter-defibrillator. Eur Heart J 1995;16:218-222

66. Lessmeier TJ, Lehmann MH, Steinman RT, Fromm BS, Akhtar M, Calkins H, DiMarco JP, Epstein AE, Estes NAM, Fogoros RN, Marchlinski FE, Wilber DJ: Outcome with implantable cardiovert- er-defibrillator therapy for survivors of ventricular fibrillation secondary to idiopathic dilated cardiomyopathy or coronary artery disease. Am J Cardiol 1993;72:911-915

67. Tchou PJ, Kadri N, Anderson J, Caceres JA, Jazayeri M, Akhtar M: Automatic implantable cardioverter defibrillators and survival of patients with left ventricular dysfunction and malignant ventricular arrhythmias. Ann Intern Med 1988: 109:529-534

68. Fogoros RN, Elson JJ, Bonnett CA, Fiedler SB. Burkholder JA: Efficacy of the automatic implantable cardioverter-defibrillator in prolonging survival in patients with severe underlying cardiac disease. J Am Coll Cardiol 1990:381-386

69. Sweeney MO, Ruskin JN, Garan H, McGovern BA, Guy ML. Torchiana DF: Influence of the implantable cardioverter/defibrillator on sudden death and total mortality in patients evaluated for cardiac transplantation. Circulation 1995;92:3273-3281

70. The Antiarrhythmics Versus Implantable Defibrillators (AVID) Investigators: A comparison of antiarrhythmic-drug therapy with implantable defibrillators in patients resuscitated from near-fatal ventricular arrhythmias. N Engl J Med 1997;337:1576-2583

71. Cardiomyopathy Trial Investigators: Cardiomyopathy trial. $P A C E$ 1993:16:576-58 